\title{
Ensaio sobre o método clínico na psicanálise com crianças ${ }^{1}$
}

Essay on the clinical method in children psychoanalysis

\author{
Rafaela Mota Paixão França*2 \\ Maria Consuêlo Passos*3
}

\begin{abstract}
A finalidade deste ensaio é discutir a qualidade do método clínico na psicanálise com crianças, a partir das contribuições de D. $W$. Winnicott sobre o brincar e o conceito elasticidade da técnica de S. Ferenczi. Uma vinheta ilustra como novas estratégias clínicas de escuta e enquadramento interrogam os valores metodológicos e éticos, problematizando o campo da técnica. Concluímos que a qualidade da ação terapêutica passa pelo esforço do analista em salvaguardar a capacidade criativa e livre em sua arte de psicanalisar.
\end{abstract}

Palavras-chave: Qualidade no método clínico, crianças, psicanálise, técnica

${ }^{1}$ Versão desenvolvida de trabalho intitulado "Bloco mágico uma reflexão sobre o método clínico de intervenção com crianças", apresentado no VII Congresso Internacional de Psicopatologia Fundamental e XIII Congresso Brasileiro de Psicopatologia Fundamental, realizado em João Pessoa-PB, nos dias 8 a 11 de setembro de 2016.

*2,3 Universidade Católica de Pernambuco (Recife, PE, Brasil). 


\section{Introdução}

$\mathrm{O}$ aumento da demanda de crianças em tratamento psicanalítico na contemporaneidade tem convocado pesquisadores e psicanalistas a repensar a clínica, ora reafirmando as práticas já adotadas, ora redescrevendo-as. Mais do que escrever a clínica, a redescrição (Costa, 1994) pressupõe uma tentativa de mudança de perspectiva na observação, com o intuito de encontrar novos sentidos para uma mesma questão ou, no mínimo, de recuperar o vigor de pensar a clínica com liberdade.

Ao falar em método psicanalítico de intervenção com crianças, a experiência do brincar enseja papel de destaque. Desde a proposição kleiniana de que a brincadeira estaria para a clínica com crianças como correlato à associação livre dos pacientes adultos no divã (Cintra e

750 Figueiredo, 2004) às teorizações winnicottianas que tomam a brincadeira enquanto espaço potencial (Winnicott, 1975), uma variedade de proposições teórico-clínicas fundamenta e contribui para o método psicanalítico de escuta das crianças. Mudanças técnicas, portanto, foram e continuam sendo responsáveis pela expansão e transformação no campo da psicanálise. O que nos permite lembrar que a técnica, não resta dúvida, exige uma fundamentação teórica que a sustente, da mesma maneira que o encontro com a clínica interroga e transforma o manejo que a determina. Na clínica psicanalítica não foi e nem é diferente, nela o jogo dialético permanente oscila entre a teoria que orienta a clínica e a clínica que fundamenta, funda e recria a teoria.

A noção de infantil, sabemos, corresponde a algo maior do que a infância propriamente dita, perpassa todo o arcabouço teórico da psicanálise e coloca-se como o fio condutor para pensar na emergência do sujeito do inconsciente. "Na vida mental", nos diz Freud em sua XIII Conferência Introdutória, "o que é inconsciente é também o que é infantil" (Freud, 1916/1969a, p. 252).

Engendrando um conceito substantivado que introduziu uma nova gramática, pensar o infantil em psicanálise não garante, contudo, refletir sobre os meandros da clínica com crianças. Em outras palavras, ter esse 


\section{ARTIGOS}

entendimento permite uma importante discussão sobre esses conceitos à luz da psicanálise, mas não acrescenta muito ao debate sobre o método clínico de intervenção com crianças e a formação de analistas que delas cuidam.

Se, por um lado, podemos dizer que uma das referências que confere legitimidade ao método clínico em psicanálise é operar com o inconsciente, por outro, precisamos reconhecer as diferenças que se processam no ato analítico diante de um analisando criança, adolescente ou adulto. Destacamos que a qualidade do método em psicanálise inclui a análise da transferência, o tipo de interpretação realizada, a compreensão sobre temporalidade e o manejo técnico que se processam. $\mathrm{Na}$ trilha do argumento clínico, por excelência, a pesquisa nos oferece um caminho de investigação que precisa ser considerado, qual seja, interrogar o que define a qualidade do método na psicanálise com crianças.

Partindo dessa questão, neste trabalho objetivamos analisar a qualidade do método clínico de intervenção com crianças, com base nas contribuições de Winnicott (1975) sobre o "brincar" e o "conceito de elasticidade da técnica" de Ferenczi (1928/2011). A escolha por esses autores justifica-se pela riqueza que imprimem em suas elaborações sobre a técnica, oferecendo ao estudo do método clínico em psicanálise um incremento a partir da escuta da intersubjetividade (França \& Rocha, 2015).

Para tanto, fragmentos da análise de uma menina de seis anos nortearão as reflexões sobre o que estamos chamando aqui de novas estratégias clínicas de escuta e enquadramento na clínica com crianças, oferecendo uma ilustração para a discussão sobre o método clínico. Por fim, propomos que a qualidade no método de intervenção psicanalítica com crianças, cujo ato de brincar é protagonista, precisa ser considerado em toda a sua potencialidade, não prescindindo do setting como espaço intermediário para criação.

\section{Contribuições à técnica psicanalítica: Ferenczi e Winnicott}

Em 1928 em Conferência proferida na Sociedade Húngara de Psicanálise, Ferenczi (1928/2011) apresentou suas ideias sobre o que chamou de "metapsicologia da técnica" (p. 39). Para ele, tratava-se de apresentar como o processo psicanalítico poderia se configurar num instrumento sofisticado para a compreensão do humano, seguindo como ponto de partida os "Conselhos sobre a técnica psicanalítica" de Freud. Nesse trabalho, que intitulou de "Elasticidade da técnica psicanalítica", Ferenczi desenvolveu uma de suas mais importantes contribuições ao trabalho analítico: a dimensão ética da técnica. 
Ao falar da técnica em psicanálise, portanto, Ferenczi tinha conhecimento da tópica, da dinâmica e da economia do funcionamento psíquico; mas a elas acrescentou o reconhecimento da importância do analista no setting. Isto lançou um olhar diferenciado não apenas sob a presença do analista, mas sob a experiência de afetação e a sua implicação no trabalho clínico. Como conselho técnico, destacou o tato, descrito por ele como a faculdade de 'sentir com' (Einfühlung) (Ferenczi, 1928/2011), como elemento fundamental para o manejo da situação clínica.

Justamente, essa categoria sutil - o tato - é resgatada para a criação de um estilo clínico diferenciado. Ferenczi remete o tato, cujo sentido Freud não chegou a aprofundar, à faculdade da empatia (Einfühlung), até então explorada apenas no terreno da investigação estética (Kupermann, 2008b, p. 81).

A afetação e a subjetividade do analista assumem, assim, uma nova posição no campo da técnica em psicanálise a partir desta noção de elasticidade trazida por Ferenczi. Para Kupermann (2008b), a disposição de pensar a técnica de um modo novo possibilitou uma perspectiva estética, que também pode ser compreendida como um paradigma estético-criativo para a clínica (Minerbo, 2010).

A dimensão ética, por fim, incluiria ainda a disposição do analista à análise pessoal, em respeito à segunda regra fundamental da psicanálise de "quem quer analisar os outros deve, em primeiro lugar, ser ele próprio analisado" (Ferenczi, 1928/2011, p. 31). Sobre isto, advertiu:

a única base confiável para uma boa técnica analítica é a análise terminada do analista. É evidente que num analista bem analisado, os processos de "sentir com” e de avaliação, exigidos por mim, não se desenrolarão no inconsciente, mas no nível pré-consciente. (p. 42)

Seria a partir dessa premissa, que o analista empreenderia sua higiene particular (Ferenczi, 1928/2011), tão cara e necessária a essa disponibilidade de prestar-se de maneira elástica e se oferecendo para que o seu paciente exercite seus afetos de prazer e desprazer. É portanto diante dessa dialética psicanalítica, que compreende o inconsciente do paciente e do próprio analista, que o analista se encontra em posição desconfortável, o que vem reafirmar a necessidade de uma boa análise pessoal. A saúde do analista, assim, torna-se pré-requisito para o manejo da técnica, como aponta Pinheiro (1995):

A elasticidade é, pois, essa assimilação interior dos fundamentos teóricos da prática clínica, que só pode existir por intermédio da análise pessoal dos 


\section{ARTIGOS}

analistas. Na falta da "introjeção", a elasticidade torna-se um comportamento artificial. (p. 110)

Outro aspecto a ser destacado na obra de Ferenczi diz respeito à maneira como compreende a hospitalidade. Em $A$ adaptação da família à criança, escrito em 1927, o psicanalista húngaro já discorria sobre a importância do ambiente na constituição psíquica. A propósito da chegada de um bebê na família, reposiciona os papéis entre pais e filhos, mostrando que a adaptação deve ser da família à criança e não o inverso. A recepção em casa, no caso do bebê, ou no setting, no caso do analisando, contribui para o tipo de vínculo que se estabelecerá e a maneira como serão elaboradas as experiências de vida.

Portanto, não há como refletir sobre o método clínico na psicanálise de crianças, sem considerar essa disponibilidade prévia do ambiente em ser acolhedor e receptivo às necessidades de quem está chegando. Nessa compreensão estão contidas as duas dimensões: Analista-objeto e Analista-ambiente. Uma vez integrados, emerge a partir do vínculo, a capacidade de confiar no entorno e no outro.

Para Winnicott, por sua vez, o manejo da técnica, enquanto método de intervenção com as crianças, está atrelado ao ato de brincar. A dimensão representacional da brincadeira, contudo, não é o aspecto destacado pelo autor, visto que entende ser na experimentação, e através da vivência conjunta, que os fenômenos transicionais podem se constituir. Isso leva Winnicott a introduzir a ideia de uma terceira área, um espaço entre fantasia e realidade, que não é fora e nem dentro: um espaço potencial.

Desde o início, o bebê tem experiências maximamente intensas no espaço potencial existente entre o objeto subjetivo e o objeto objetivamente percebido, entre extensões do eu e do não eu. (Winnicott, 1975, p. 139)

Ogden (2015) propõe que o espaço potencial seja compreendido em sua dimensão dialética, levando-se em consideração os paradoxos presentes na teoria winnicottiana. O interjogo contempla o que é espaço pessoal e interpessoal, o que é biológico e o que é experiência real.

A conquista de tal processo dialético ocorre por meios de um avanço do desenvolvimento a partir da "unicidade invisível" da unidade mãe-bebê para a trindade subjetiva da mãe-e-bebê (como objetos simbólicos) e o bebê (como sujeito intérprete). (p. 173) 
É a partir desse espaço que a criança pode existir e, posteriormente, aprender a jogar, a criar, a sonhar. A experiência cultural localiza-se, portanto, justamente no espaço potencial acima descrito. Em $O$ brincar e a realidade, Winnicott apresenta detalhadamente a sua rica contribuição à concepção sob a experiência criativa e a constituição do self. Em suas palavras:

É no brincar, somente no brincar, que o indivíduo, criança ou adulto, pode ser criativo e utilizar a sua personalidade integral: e é somente sendo criativo que o indivíduo descobre o eu (self). (Winnicott, 1975, p. 80)

O que nos mostra que sua compreensão sobre o brincar transpõe a ação e contempla a dimensão da existência. Para Winnicott, a experiência criativa começa no viver criativo, manifestado primeiramente na brincadeira, cujos desdobramentos se apresentam como uma vida genuinamente vivida e uma experiência na continuidade espaço-tempo, conferindo existência e continuidade ao ser. Mas para que tudo isso aconteça é necessária a constituição de uma atmosfera de confiabilidade, um ambiente suficientemente cuidadoso às necessidades do bebê.

Estas ideias também são reconhecidas por Winnicott como elementos

754 importantes na compreensão sobre o manejo e sobre as relações entre analista-analisando. No campo da técnica de intervenções com crianças, cabe lembrar que a psicoterapia se dá no encontro entre essas duas áreas lúdicas: a do paciente e a do analista. A brincadeira comporta essas duas faces criativas e precisa ser genuinamente vivida pela dupla nas sessões.

Tornando-se disponível com sua presença, o analista empresta elementos capazes de possibilitar o gradual restabelecimento da capacidade de fruição das potencialidades individuais do sujeito, proporcionando um suporte para o processo de integração e para a recuperação da experiência de continuidade do ser. (Klautau \& Salem, 2009, p. 52)

O caso Bruna

Gostaríamos de iniciar este relato fazendo a seguinte ressalva: a análise deste caso não pôde desprezar a tênue fronteira que separa os pressupostos teóricos, o enquadramento utilizado e o estilo pessoal da analista. ${ }^{1}$ As escolhas

${ }^{1}$ Este caso foi atendido por Rafaela Paixão entre 2014 e 2018. 


\section{ARTIGOS}

técnicas feitas são de sua inteira responsabilidade e, em princípio, não trazem a intenção de se apresentar como proposta de intervenção, mas tão somente como um exemplo das redescrições que a clínica nos convoca a fazer continuamente.

Os pais de Bruna, então com seis anos, $\mathrm{me}^{2}$ procuraram preocupados com a maneira introvertida e pouco argumentativa da filha para lidar com suas próprias dificuldades. Descreviam a criança como uma menina alegre, cheia de disposição, mas excessivamente tímida com estranhos ou situações novas. As queixas eram de que a criança estaria apresentando uma 'implicância' para se alimentar, associada a uma recusa em dar continuidade às aulas de natação nos últimos meses, além de muito choro e grito diante das frustrações.

A história familiar de Bruna parecia não apresentar nada que justificasse tal inquietude e introspecção. Seus pais mostravam-se acessíveis, com disponibilidade para escutar as dificuldades da filha e oscilavam seu discurso entre entender a postura da criança como uma fase ou tomar como uma tentativa de controle do ambiente familiar. Em minha escuta, entretanto, não podia deixar ainda de considerar que, entre as questões de Bruna, misturavam-se as angústias de Rosa (sua mãe), que na ocasião também se adaptava à chegada da filha mais nova.

Apesar de manifestar expressões neuróticas comuns na infância, $o$ sintoma apresentado pela criança, acenava para a necessidade de um olhar mais apurado para o seu entorno. A partir de uma escuta winnicottiana, o diagnóstico na infância encontra um enquadramento clínico que vai nessa direção porque não apenas leva em consideração a condição de maturação e dependência vividas pela criança a cada tempo do processo de amadurecimento, mas irá valorizar os modos de relação com o ambiente no qual a criança está inserida.

Winnicott (2007c) afirma ser "válido classificar de acordo com o grau e qualidade da distorção ambiental, ou de sua deficiência, que pode ser reconhecida como etiologicamente significativa" (p. 125). Partindo dessa compreensão, foi possível reconhecer que as dificuldades de Bruna correspondiam a uma imaturidade psicológica, que somada às ansiedades

${ }^{2}$ A partir deste momento, usaremos a primeira pessoa do singular para facilitar a leitura e a discussão da vinheta apresentada. 
decorrentes desta, lançavam a criança numa relação de dependência com sua mãe e vinha produzindo angústias diante das experiências de separação. "Um distúrbio psicológico significa imaturidade, imaturidade do crescimento emocional do indivíduo, e esse crescimento inclui a evolução da capacidade do indivíduo de se relacionar com pessoas e com o ambiente de modo geral" (Winnicott, 2005, p. 96).

O primeiro ano do processo analítico de Bruna correspondeu a um tempo de elaboração das recentes mudanças na família por parte da criança, o que incluía, em meu trabalho, atendimentos sistemáticos aos pais. Sua forma de se comunicar e estar comigo nas sessões sempre incluía uma presença ativa de minha parte, praticamente conduzindo o que era dito ou produzindo em nossas brincadeiras. Por um longo tempo ela privilegiou nas sessões os desenhos que fazíamos para os ursinhos de pelúcia que ela trazia a cada sessão. Normalmente dois, um para mim e outro para ela. A nossa brincadeira consistia em construir casas ou habitats para eles, o que tomava a maior parte do tempo da sessão, restando-nos ao final um curto momento em que brincávamos com os bichinhos por cima dessas produções.

A comunicação era predominantemente construída dessa maneira e 756 Bruna demandava de mim não só um desenho, como a condução da história que criávamos a cada encontro, normalmente orientado pela minha fala. Sua voz aparecia pontualmente, sendo necessário, em geral, que eu pudesse falar por ela ou dizer algo para que ela, só então, pudesse dar voz aos seus personagens. Como nos lembra Winnicott (2007a), nos estágios iniciais da análise isso corresponde ao apoio dado ao ego pela mãe que torna forte o ego da criança (p. 154). Essa fase temporária, parte especial do desenvolvimento, era encenada por Bruna nesse primeiro tempo da análise, o que exigiu de mim, tal como uma mãe suficientemente boa, uma presença implicada no seu movimento da dependência absoluta rumo à dependência relativa (Winnicott, 2007b, p. 48). Gradativamente, ela parecia amadurecer. Passei a ter notícias do quanto ela estava diferente, mais expressiva, com maior segurança e menos desconfiada.

No final do ano, contudo, a propósito da troca de escola prevista, Rosa começou a solicitar vir no horário da sessão da filha para falar das suas preocupações com as futuras mudanças. Entre o medo da filha não se adaptar a uma escola maior e o receio de ela ter dificuldades para fazer novos amigos, Rosa inquietava-se com a decisão de matricular Bruna na escola que ela estudou na infância ou aventurar-se a ir para a escola que as amigas da criança iam. A ansiedade diante disso se apresentou de maneira muito intensa para Rosa e, percebendo a fragilidade dela, passei a atender os pais com 


\section{ARTIGOS}

maior frequência nesse período. Mais tranquilo, o pai não via uma questão a ser superada por Bruna; em sua percepção, Rosa estava inquietando-se mais do que deveria com uma experiência que ele considerava simples na vida da filha. Rosa, contudo, chorava e angustiava-se com quase tudo que dizia respeito ao comportamento de Bruna, destacando a todo momento seu receio. A lembrança da difícil adaptação de Bruna na primeira escola reforçava a razão da antecipação de Rosa.

Entendendo que "o processo de maturação depende, para se tornar real na criança, e real nos momentos apropriados, de favorecimento ambiental suficientemente bom" (Winnicott, 2007d, p. 91), fui percebendo que um trabalho de análise para Rosa se fazia necessário. Minha escuta se dirigiu a oferecer espaço e tempo de análise para a escuta da mãe dessa criança. Houve uma decisão deliberada de atendê-la, frente à percepção de que o sofrimento de Bruna tinha relação direta com as dificuldades de Rosa; o vínculo entre elas era um aspecto a ser analisado. Em seu trabalho "Família e maturidade emocional", Winnicott (2013) traduz a árdua tarefa da mãe, e depois também do pai, de atender às necessidades do indivíduo, tarefas que incluem "ademais, em aceitar as irrupções de rebeldia e as recaídas na dependência que se seguem à rebeldia" (p. 131).

Costumamos, antes de redirecionar os pais à análise individual, pensar as possibilidades de cuidar da família, escutar o seu sofrimento e a forma como se vinculam aos sintomas da criança em questão numa tentativa de investigar as tramas familiares e transgeracionais que perpassam o caso. Essa escuta, normalmente, tende a ser um terreno fértil para uma futura análise dos pais, na mesma medida em que se configura num potente motor que faz girar a engrenagem da análise da criança em questão. Esse trabalho de escuta da mãe apresentava-se como uma possibilidade de analisar a rebeldia e a dependência de Bruna à sua mãe.

Assim decidi escutar o pedido de Rosa, que continuava me solicitando vir no horário da filha. Apesar de não haver nenhum impedimento para que ela estivesse nos atendimentos em outro dia/horário, alguma coisa me impelia a aceitar sua demanda e considerar uma mudança no enquadramento dessa análise. Ainda hoje, não conseguiria dizer as razões pelas quais aceitei esse formato de atendimento. Mas, assim como era clara para mim a necessidade de a mãe vir falar sistematicamente sobre a sua filha, era claro também que não havia nada que a impedisse de vir num horário diferente.

É comum, quando trabalhamos com crianças, que os atendimentos de pais a propósito da análise dos seus filhos aconteçam no próprio espaço de 
atendimento da criança. O que eu estranhava, mesmo com essa familiaridade, era a razão pela qual eu havia decidido escutar Rosa no horário de Bruna em atendimentos alternados e sistemáticos, configurando o que parecia ser um novo enquadramento do caso.

A mudança do enquadramento, responsável por lançar esse novo formato de escuta e atendimento, foi explicitado e trabalhado com o par mãe-filha. Frente ao reconhecimento das necessidades de ambas, propus essa variação que foi facilmente aceita pela dupla. Para Rosa, foi recebido como uma abertura minha para escuta do seu sofrimento com a filha, enquanto para Bruna, apresentou-se, inconscientemente, como uma divisão do sintoma, já que agora sua mãe era convocada a ir às sessões sem ela. A propósito de receber os pais no trabalho analítico com as crianças, Macedo (2012) acredita que "ao fazê-lo, o psicanalista cuida do amor próprio deles, ajuda-os a suportar melhor a rivalidade com o terapeuta - é sempre uma ferida levar o filho para a terapia - e trata a inveja inconsciente que acompanha a atenuação de seus sofrimentos" (p. 12).

Caminhando com Ferenczi (1928/2011), que em "Elasticidade da técnica psicanalítica" adotou conceitos como tato e empatia para falar sobre a 758 flexibilidade necessária ao trabalho analítico, permiti que o atendimento à mãe ocorresse no horário da criança, alternadamente. Tal como uma tira elástica, prestei-me ao papel de intercalar a escuta de Bruna com a de sua mãe, ora me distanciando, ora me aproximando dos afetos experimentados por cada uma delas, a cada sessão. Mas, ao escolher atender Bruna e Rosa em sessões alternadas por vários meses, eu ainda hesitava, me questionando o que estaria motivando a minha decisão (inconsciente) de romper o enquadre padrão.

Crescia em mim, a cada atendimento que fazia separadamente, da mãe ou da filha, a convicção de que os efeitos do processo se colocavam para as duas. Bruna recebia agora de sua mãe uma via de acesso para a constituição de si, enquanto Rosa, ao falar $d a$ filha e por ela, acessava às suas próprias experiências infantis e retomava a criança que um dia fora. Passou ainda a analisar, a partir da análise da filha, o exercício da maternidade, enquanto a criança construía um novo modo de estar no mundo.

\section{Discussão}

Por que a analista aceitou alternar os atendimentos entre as duas? Por que, mesmo sentindo como uma necessidade, a decisão lhe causou tanto 


\section{ARTIGOS}

desconforto e estranhamento? A empatia e a intuição de seguir escutando o caso, flexibilizando o enquadramento, como começou a fazer, no início não se apresentava a ela como um pensamento clínico. Para Green, o pensamento clínico é "uma forma original e específica de racionalidade que emerge da experiência prática" (Green, 2002, apud Minerbo, 2014, p. 216). Aquilo que permite desfazer a dicotomia entre teoria e clínica nos fazendo avançar sobre o caso e os conceitos. Ela não tinha construído uma formulação de intervenção que seria, a partir de então, o método de intervenção para aquela escuta. Nesse sentido, não havia um pensamento clínico até então, ela apenas fazia.

Explicamos melhor: não havia uma hipótese clara do que a levou a aceitar esse modo de escutar Bruna e Rosa, mas o fato é que, ao acolher o que espontaneamente se colocava nesse caso, ela abria espaço para a experiência viva da clínica. Como nos lembra Stefano Bolognini (2008) em seu livro A empatia psicanalítica, em situações como essa estamos diante de novas dimensões e mudanças técnicas da psicanálise, cuja ênfase estaria no campo intersubjetivo. Para ele, faltam descrições relevantes a respeito da riqueza da práxis, especialmente porque "é difícil formular os conceitos que organizam teoricamente nossas observações” (p. 129). Assim, a experiência compartilhada não é apenas de difícil descrição, mas nos convoca a exercer a ética psicanalítica diante da imprevisibilidade dos casos.

Apesar de reconhecermos a necessidade do psicanalista desenvolver a sua sensibilidade clínica trabalhando de maneira empática, consideramos que parte fundamental do seu trabalho consiste em, continuamente, debruçar-se sobre sua prática, o que inclui a articulação permanente entre as questões teórico-técnicas. Pensando nisso, lançamos um questionamento a partir da análise desse caso: o que define a qualidade do método na psicanálise, especialmente, na psicanálise com crianças?

Aquilo que parecia uma quebra de enquadramento no formato de atendimento em padrão, apontava, podemos hoje dizer, para uma abertura, uma flexibilização do enquadre clínico, cuja versatilidade remete ao que há de mais imperativo em nosso trabalho: a soberania da clínica. A disposição para "ceder às tendências do paciente, mas sem abandonar a tração na direção de suas próprias opiniões”, nos lembra Ferenczi (2011, p. 37), é papel fundamental da técnica. Essa força que incide sobre o ato de psicanalisar, lança continuamente o analista em questões antes impensáveis, promove rupturas com ideias preconcebidas, interroga o enquadre e a técnica, para, por fim, criar novos enquadres clínicos. Segundo Aiello-Vaisberg (2004), 
"diferentes enquadres, cuja diversidade é sustentada pela invariabilidade do método" (p. 9).

Sensível à narrativa clínica que se processava, a condução flexível nesse caso, a partir de um enquadramento diferenciado, não resta dúvida, produziu novos sentidos para a escuta da analista. $\mathrm{O}$ enquadre possível passou a ser a oferta de um espaço cuja transicionalidade produzia a criação de "mundos temporários voltados ao favorecimento de certo tipo de acontecer" (Aiello-Vaisberg, 2004, p. 10).

A chave para o desenlace do caso começou a se esclarecer quando a analista pôde experimentar o que estava se dando no setting terapêtico, a saber, a elaboração da experiência de presença/ausência, tal como a conhecida brincadeira de fort-da (Freud, 1920/1969b). Ao modificar o dispositivo de escuta, Bruna e Rosa, tal como "brincadeira", apareciam e desapareciam, ao mesmo tempo que oscilavam entre ser/não ser objeto de análise. Além disso, elas se faziam aparecer e desaparecer uma para a outra no enfrentamento das questões que as ligavam. O que nos permite pensar que a análise através do jogo de presença-ausência se transformou numa comunicação cruzada: que compreendeu a comunicação das duas, entre si, e a comunicação delas com a analista.

Podemos pensar ainda que o ritmo que se imprimiu às sessões trouxe para Bruna uma apresentação do mundo em pequenas doses (Winnicott, 1982). A confiança no vínculo mãe-filha, a partir do que se reatualizava na transferência com a analista, operou uma separação, objetiva e subjetivamente falando. Em outras palavras, esse jogo contínuo que se processou no setting, transformou o próprio enquadramento num espaço potencial que deu forma à área de ilusão - necessária para que a separação entre Bruna e sua mãe pudesse se efetivar.

Parafraseando a teoria do brincar proposta por Winnicott (1975), podemos dizer que Rosa se achava num permanente oscilar entre ser o que Bruna tinha capacidade de encontrar e, alternativamente, ser ela própria, aguardando ser encontrada. O setting terapêutico, diante dessa proposição de sistemática de atendimento variável, produziu entre as três (analista-mãe-filha) um brincar compartilhado, oferecendo novos sentidos à análise que se encaminhava. A presença efetiva da analista, em sua corporeidade e ação, permitiu não apenas que a brincadeira emergisse entre as duas - ao terem a experiência de criar-encontrar um lugar para viver —, como a análise constituía-se num espaço para comunicação diante da partilha de experiências que se davam a cada sessão. 


\section{ARTIGOS}

O brincar assumiu, assim, a dianteira do método de tratamento psicana-lítico e fundamentou suas intervenções. Segundo Fulgêncio (2008), uma "meto-dologia clínica centrada não tanto na interpretação, mas num determinado tipo de relação, encontro e comunicação entre paciente e analista" (p. 127). Devemos compartilhar aqui que mais de uma vez a analista se perguntou como faria "tudo voltar ao normal", em referência ao 'enquadre padrão', cuja escuta dos pais é realizada em horário e dia diferentes do da criança, além de não manter uma sistemática previamente definida. Nessas horas de reflexão intensa e de certa angústia produtiva foi comum à analista ser perpassada por um sentimento de desconforto; a dúvida de estar cometendo um grande equívoco reaparecia a todo momento. Contudo, não demorou para que uma conviç̧ão, não encontramos outra palavra, a levasse rapidamente a acreditar que o manejo peculiar que passava a exercer na escuta desse caso acenava para uma necessidade (imperativa) da sua escuta implicada da díade (Bruna-Rosa).

A partir dessa experiência, podemos dizer que o próprio setting e, por conseguinte, o enquadramento em questão, mesmo apresentando um formato peculiar, não perdeu aquilo que consideramos fundamental ao processo analítico: a escuta clínica, por excelência. A questão retorna: qual o fundamento e a razão que conferem qualidade ao método psicanalítico?

A liberdade de agir que levou a analista a se emprestar como um 'objeto intermediário' dessa díade, através do qual mãe e filha puderam fazer uso, até que esta tivesse se tornado dispensável, continuou sendo um dos motivos da manutenção desse formato de atendimento por mais de um ano. Para Winnicott (1975), o "uso de objeto" só é possível após ter-se constituído a capacidade de se "relacionar com o objeto". O sujeito encontra o objeto e o destrói; mas o objeto sobrevive a essa destruição e, então, fora do controle onipotente, o objeto real poderá ser amado e usado tal como é.

A análise de Bruna parece ter reeditado a elaboração dessa experiência transicional. Tal como a criança que usa seu brinquedo até dele se desfazer porque ele perdeu o sentido, a analista (mãe-objeto) e, por conseguinte, o setting (mãe-ambiente) foram oferecidos para serem usados por Bruna e Rosa, até que elas pudessem prescindir deles. Aos poucos, foram abrindo espaço para outras criações - entre si e separadamente. Uma conquista que passou pela elaboração da separação entre elas, e foi reeditada a partir do que se processava no espaço analítico. Nas palavras de Winnicott (1975):

Por "uso" não quero significar "exploração". (...) Muitos de nossos pacientes chegam-nos com esse problema já solucionado: podem usar objetos, podem 
usar-nos e podem usar a análise, tal como usaram seus pais, seus irmãos e seus lares. Entretanto, muitos pacientes necessitam adquirir, através de nós, uma capacidade de nos usar. Esta é, para eles, a tarefa analítica. (p. 130)

Segundo Neville Symington (1994), "a alma da técnica analítica é liberar tanto analista quanto paciente das coerções sociais normais e, assim, favorecer o desenvolvimento do mundo interior" (p. 190). A partir desse caso, então, podemos afirmar que o ato interno de liberação do analista produz mudanças no paciente e aprendizado para o analista. Reconhecemos que o aumento da confiança nesse formato de escuta por parte da analista, promoveu mudanças não apenas em Bruna e em sua mãe, como lançou insights interessantes ao complexo universo da psicanálise com crianças.

A autonomia de intervir tecnicamente com liberdade não trouxe menos dúvida ou mais segurança, ao contrário, continuou produzindo incertezas ao trabalho analítico proposto, em especial, trouxe incertezas aos possíveis desfechos da análise. Mas a experiência de se emprestar como analista promovendo uma área de ilusão para mãe e filha, acenou para o papel da técnica sensivel (Kupermann, 2008a,b) como um terreno fértil ao processo transformacional (Bollas, 2015).

A separação esperada entre Bruna e sua mãe começou realmente a acontecer ao longo do processo analítico. Não apenas Bruna voltou a pedir para vir mais vezes, sugerindo um retorno ao formato de encontros semanais, como Rosa passou a solicitar diminuir os encontros com a analista. A sistemática de sessões alternadas foi reduzida e, tal como um desmame, foi sugerido que Rosa passasse a vir sempre na última sessão do mês, ainda no horário da filha, sendo as demais sessões reservadas apenas a Bruna. Parece que finalmente puderam prescindir desse jogo de presença-ausência que se efetuou com a analista e o enquadre previsto até então, deixou de fazer sentido, dando lugar a um novo acordo. Bruna começou a alternar as brincadeiras nas sessões; entre os desenhos que foram a marca do início da sua análise e a introdução de jogos de tabuleiro, uma novidade em seu processo. Ironicamente, seu jogo preferido passou a ser o Jogo da vida e quando era dia de jogar, sempre dizia: "eu quero viver!”. Analista e paciente riam.

\section{Considerações finais}

Ao apresentar, discutir e fundamentar os fragmentos desse caso clínico, nosso propósito consistiu não apenas em revisitar o sistema de 


\section{ARTIGOS}

valores analíticos que fundamentam o método clínico em psicanálise, mas configurou-se, ainda, numa tentativa de propor um questionamento acerca do ato de psicanalisar crianças. Acreditamos que o manejo escolhido na intervenção com Bruna acena a importância de o analista atender às necessidades de dependência de seu paciente, tal como concede uma mãe suficientemente boa. Nas palavras de Winnicott (1975): "o amor da mãe, ou do terapeuta, não significaria apenas um atendimento às necessidades da dependência, mas vem a significar a concessão de oportunidade que permita ao bebê, ou ao paciente, passar da dependência para a autonomia" (p. 150).

Podemos afirmar que a qualidade da intervenção psicanalítica com crianças pode ser definida, sobretudo, pela oferta de um contexto clínico capaz de contribuir para a criação de uma experiência potencialmente nova. Um espaço que inspire a confiança necessária para a criança brincar criativamente e entrar em contato com suas heranças culturais e familiares. Reside ainda na capacidade de "esperar pela evolução natural da transferência que surge da confiança crescente do paciente na técnica e no cenário psicanalítico" (Winnicott, 1975, p. 121).

Uma técnica elástica e capaz de sustentar 'como brincadeira' a presença dos pais no setting e a alternância das sessões feitas com a criança ou para ela, mostrou-se neste trabalho como aporte ao debate sobre método clínico na psicanálise com crianças. Reafirmando, assim, que a soberania da clínica e o respeito ao ineditismo de cada caso ainda se impõem como motor para a pesquisa e tratamento em psicanálise, em qualquer tempo.

Ao pensar as relações entre método, técnica e enquadramento na psicanálise com crianças recolocamos como questão não apenas os valores metodológicos, como revisitamos os dilemas éticos, aqui tomados em referência às práticas de cuidado, que atravessam o ofício de todo psicanalista. Nele, residiria o ato de brincar tomado como modelo do método de tratamento psicanalítico, assim como o reconhecimento de que a qualidade da ação terapêutica passa pelo esforço do analista em ser demasiadamente humano, ter seus próprios pensamentos e salvaguardar a capacidade criativa e espontânea em sua arte de psicanalisar (Odgen, 2010). Sigamos, portanto, brincando.

\section{Referências}

Aiello-Vaisberg, T. M. J. (2004). Os enquadres Clínicos Diferenciados e a Personalização/Realização Transicional. Cadernos Ser e Fazer: O Brincar (pp. 
6-17). Recuperado de:<http://serefazer.psc.br/wp-content/uploads/2012/09/textoTania-caderno-laranja.pdf $>$.

Aguiar, F. (2001). Método clínico: método clínico?. Psicologia: Reflexão e Crítica, 14(3), 609-616. Recuperado de: <https://dx.doi.org/10.1590/S0102$79722001000300016>$.

Bollas, C. (2015). A sombra do objeto: psicanálise do conhecido não pensado. São Paulo, SP: Escuta.

Bolognini, S. (2008). A empatia psicanalitica. Rio de Janeiro, RJ: Cia. de Freud.

Cintra, E. M. U., \& Figueiredo, L. C. (2004). A clínica kleiniana: estilo, técnica e ética. In Melanie Klein: estilo e pensamento (pp. 171-188). São Paulo, SP: Escuta.

Costa, J. F. (1994). Redescrições da psicanálise: ensaios pragmáticos. Rio de Janeiro, RJ: Relume-Dumará.

Ferenczi, S. (2011). Elasticidade da técnica psicanalítica. In S. Ferenczi, Psicanálise IV (pp. 29-42). São Paulo, SP: Martins Fontes. (Trabalho original publicado em 1928).

França, R. M. P., \& Rocha, Z. (2015). Por uma ética do cuidado na psicanálise da criança. Psicologia USP, 26(3), Recuperado de: <http://www.scielo.br/pdf/pusp/ v26n3/1678-5177-pusp-26-03-00414.pdf>.

Freud, S. (1969a). Aspectos arcaicos e infantilismo dos sonhos. In Edição Standard Brasileira das Obras Psicológicas Completas de Sigmund Freud (v. XVI). Rio de Janeiro, RJ: Imago. (Trabalho original publicado em 1916).

Freud, S. (1969b). Além do princípio de prazer. In Edição Standard Brasileira das Obras Psicológicas Completas de Sigmund Freud (v. XVIII) Rio de Janeiro, RJ: Imago. (Trabalho original publicado em 1920).

Fulgêncio, L. (2008). O brincar como modelo do método de tratamento psicanalítico. Revista Brasileira de Psicanálise, 42(1), 123-136. Recuperado de: <http://pepsic. bvsalud.org/scielo.php?script=sci_arttext\&pid=S0486-641X2008000100013\&lng $=\mathrm{pt} \& \mathrm{t} \operatorname{lng}=\mathrm{pt}>$.

Klautau, P., \& Salem, P. (2009). Dependência e construção da confiança: A clínica psicanalítica nos limites da interpretação. Natureza humana, 11(2), 33-54. Recuperado em 1 abr. 2019, de: <http://pepsic.bvsalud.org/scielo.php?script=sci arttext\&pid $=\mathrm{S} 1517-24302009000200002 \& \operatorname{lng}=\mathrm{pt} \& \operatorname{lng}=\mathrm{pt}>$.

Kupermann, D. (2008a). Presença sensível: cuidado e criação na clínica psicanalítica. Rio de Janeiro, RJ: Civilização Brasileira.

Kupermann, D. (2008b). Presença sensível: a experiência da transferência em Freud, Ferenczi e Winnicott. Jornal de Psicanálise, 41(75): 75-96, dez.

Macedo, H. O’D. (2012). Cartas a uma jovem psicanalista. São Paulo, SP: Perspectiva.

Mezan, R. (1998). Escrever a clínica. São Paulo, SP: Casa do Psicólogo. 


\section{ARTIGOS}

Minerbo, M. (2010). Presença sensível. Revista Brasileira de Psicanálise, 44(2), 185-187. Recuperado em 2 abr. 2019, de: <http://pepsic.bvsalud.org/scielo. php?script=sci_arttext\&pid=S0486-641X2010000200019\&lng=pt\&tlng=pt $>$.

Minerbo, M. (2014). Pensamento clínico: diálogo com um jovem colega. Jornal de Psicanálise, 47(87), 215-230. Recuperado de: <http://pepsic.bvsalud.org/scielo. php?script=sci_arttext\&pid=S0103-58352014000200013\&lng=pt\&tlng=pt $>$.

Ogden, T. H. (2010). Esta arte da psicanálise: sonhando sonhos não sonhados e gritos interrompidos. Porto Alegre, RS: Artmed.

Ogden,T. H. (2015). A matriz da mente: relações objetais e o diálogo psicanalítico. Londres, UK: Karnac Books.

Pinheiro, T. (1995). Ferenczi: do grito à palavra. Rio de Janeiro, RJ: Jorge Zahar/ Ed. UFRJ.

Symington, N. (1994). O ato de liberação do analista como agente de mudança terapêutica. In A Escola Britânica de Psicanálise: The Middle Group, A tradição independente. Porto Alegre, RS: Artes Médicas.

Winnicott, D. D. (1975). O brincar e a realidade. Rio de Janeiro, RJ: Imago.

Winnicott, D. D. (1982). O mundo em pequenas doses. In D. W. Winnicott, A criança e o seu mundo (6 ${ }^{\mathrm{a}}$ ed.). Rio de Janeiro, RJ: LTC.

Winnicott, D. W. (2005). Tipos de psicoterapia. In D. W. Winnicott, Tudo começa em casa (4a ed., pp. 93-104). São Paulo, SP: Martins Fontes.

Winnicott, D. W. (2007a). Os objetivos do tratamento psicanalítico. In D. W. Winnicott, $O$ ambiente e os processos de maturação (pp.152-155). Rio de Janeiro, RJ: Imago.

Winnicott, D. W. (2007b). Teoria do relacionamento paterno-infantil. In D. W. Winnicott, $O$ ambiente e os processos de maturação (pp. 38-54). Rio de Janeiro, RJ: Imago.

Winnicott, D. W. (2007c). Classificação: existe uma contribuição psicanalítica à classificação psiquiátrica? In D. W. Winnicott, $O$ ambiente e os processos de maturação (pp. 114-127). Rio de Janeiro, RJ: Imago.

Winnicott, D. W. (2007d). Moral e educação. In D. W. Winnicott, $O$ ambiente e os processos de maturação (pp. 88-98). Rio de Janeiro, RJ: Imago.

Winnicott, D. W. (2013). Família e maturidade emocional. In D. W. Winnicott, $A$ família e o desenvolvimento individual (pp. 129-138). São Paulo, SP: Martins Fontes. 


\section{Resumos}

(Essay on the clinical method in children psychoanalysis)

The purpose of this essay is to discuss the quality of the clinical method in children psychoanalysis, based on the contributions by D.W. Winnicott regarding the play and the elasticity concept of the S. Ferenczi technique. A vignette illustrates how new clinical strategies of listening and framing interrogate methodological and ethical values, problematizing the field of technique. We conclude that the quality of the therapeutic action goes through the analyst's effort to safeguard the creative and free capacity in his art of performing psychoanalysis.

Key words: Quality in the clinical method, children, psychoanalysis, technique

(Essai sur la méthode clinique en psychanalyse avec des enfants

Le but de cet essai est de discuter la qualité de la méthode clinique en psychanalyse chez des enfants, à partir des contributions de D.W. Winnicott sur le concept de jeu et d'élasticité de la technique de S. Ferenczi. Une vignette illustre comment de nouvelles stratégies cliniques d'écoute et de cadrage interrogent des valeurs méthodologiques et éthiques, rendant problématique le domaine de la technique. Nous concluons que la qualité de l'action thérapeutique passe par l'effort de l'analyste dans la sauvegarde de la capacité créative et libre dans l'exercice de son art de la psychanalyse.

Mots clés: Qualité dans la méthode clinique, enfants, psychanalyse, technique

(Ensayo sobre el método clínico en el psicoanálisis con niños)

La finalidad de este ensayo es discutir la calidad del método clínico en el psicoanálisis con niños, desde las contribuciones de D. W. Winnicott sobre el juego $y$ el concepto elasticidad de la técnica de S. Ferenczi. Una viñeta ilustra cómo nuevas estrategias clínicas de escucha y encuadramiento interrogan los valores metodológicos y éticos, problematizando el campo de la técnica. Concluimos que la calidad de la acción terapéutica pasa por el esfuerzo del analista para salvaguardar la capacidad creativa y libre en su arte de psicoanalizar.

Palabras clave: Calidad en el método clínico, niños, psicoanálisis, técnica

(Essay über die klinische Methode in der Psychoanalyse mit Kindern)

Dieser Artikel diskutiert die Qualität der klinischen Methode in der Psychoanalyse von Kindern anhand der Beiträge von D. W. Winnicott über das Spiel und das Konzept der Elastizität der Technik von S. Ferenczi. Eine Vignette veranschaulicht, wie neue klinische Strategien des Zuhörens und des Einstufens methodische und ethische Werte in Frage stellen und die Technik problematisieren. Wir schließen daraus, dass die Qualität der therapeutischen Wirkung von den 


\section{ARTIGOS}

Bemühungen des Analytikers getragen wird, die schöpferischen und freien Fähigkeiten seiner psychoanalytischen Vorgehensweise zu sichern.

Schlüsselwörter: Qualität in der klinischen Methode, Kinder, Psychoanalyse, Technik

Citação/Citation: França, R. M. P., \& Passos, M. C. (2019, dez.). Ensaio sobre o método clínico na psicanálise com crianças. Revista Latinoamericana de Psicopatologia Fundamental, 22(4), 749-767. http://dx.doi.org/10.1590/1415-4714.2019v22n4p749.6.

Editora/Editor: Profa. Dra. Sonia Leite

Submetido/Submitted: 9.11.2018 11.9.2018～Revisado/Revised: 4.4.2019/4.4201

Aceito/Accepted: 13.9.2019/9.13.2019

Copyright: (C) 2009 Associação Universitária de Pesquisa em Psicopatologia Fundamental/ University Association for Research in Fundamental Psychopathology. Este é um artigo de livre acesso, que permite uso irrestrito, distribuição e reprodução em qualquer meio, desde que o autor e a fonte sejam citados / This is an open-access article, which permits unrestricted use, distribution, and reproduction in any medium, provided the original authors and sources are credited.

Financiamento/Funding: Este trabalho não recebeu apoio / This work received no funding.

Conflito de interesses/Conflict of interest: As autoras declaram que não há conflito de interesses. / The authors declare that there is no conflict of interest.

\section{Rafaela Mota Paixão França}

Doutoranda em Psicologia Clínica na Universidade Católica de Pernambuco (Recife, PE, Br); Bolsista CAPES/PROSUC; Psicóloga do Centro de Pesquisa em Psicanálise e Linguagem - CPPL (Recife, PE, Br); Psicanalista do Círculo Psicanalítico de Pernambuco (Recife, PE, Br).

Rua Cardeal Arcoverde, 308 - Graças

52011-240 Recife, PE, Br

rafampaixao@hotmail.com

https://orcid.org.0000-0003-2869-6778

\section{Maria Consuêlo Passos}

Psicóloga; Psicanalista de casal e família; Doutora em Psicologia Social; Docente-pesquisadora do Programa de Pós-Graduação em Psicologia Clínica da Universidade Católica de Pernambuco (Recife, PE, Br).

Rua Zeferino Galvão, 100/903 - Boa Viagem

51111-110 Recife, PE, Br mariaconsuelopassos@gmail.com

https://orcid.org.0000-0001-8797-8893

This is an open-access article, which permits unrestricted use, distribution, (cc) BY-NC and reproduction in any medium for non-commercial purposes provided the original authors and sources are credited. 